\title{
Process Mapping to Examine How Goals of Care Discussions and Decisions about Life-Sustaining Treatments Occur On Medical Wards: A Multi- Center Observational Study
}

Dev Jayaraman, MD, MPH, Nishan Sharma, MSc, EdD, Alannah Smrke, MD, Jessica Simon, MB ChB, FRCPC, Peter Dodek, MD, MHSc, Daren K. Heyland, MD, MSc, John J. You, MD, MSc

\section{About the Authors}

Dev Jayaraman, MD, MPH, is with the Departments of Medicine and Critical Care, McGill University, Montreal, Quebec, Canada Nishan Sharma, MSc, EdD, is with the Department of Community Health Sciences, University of Calgary, Calgary, Alberta, Canada Alannah Smrke, MD, is with the Division of Medical Oncology, Department of Medicine, University of British Columbia,

Vancouver, British Columbia, Canada

Jessica Simon, MB ChB, FRCPC, is with the Departments of Oncology, Medicine and Community Health Sciences, University of Calgary, Calgary, Canada

Peter Dodek, MD, MHSc, is with the Center for Health Evaluation and Outcome Sciences and Division of Critical Care Medicine, University of British Columbia and St. Paul's Hospital, Vancouver, British Columbia, Canada

Daren K. Heyland, MD, MSc, is with the Department of Critical Care Medicine, Queen's University, Kingston, Ontario, Canada John J. You, MD, MSc, is with the Department of Medicine, division of General and Hospitalist Medicine, Trillium Health Partners, Mississauga, Ontario, Canada Corresponding Author: John.You@thp.ca

Submitted: February 2, 2019. Accepted: August 9, 2019. Published: February 28, 2020. DOI: 10.22374/cjgim.v15i1.344

\section{Abstract Background}

Poor quality communication about goals of care with seriously ill, hospitalized patients is associated with substantial discordance between prescribed medical orders for life-sustaining treatment and patients' stated preferences. Designing tailored solutions to this discordance requires a better understanding of this communication process.

\section{Objective}

To acquire a detailed understanding of the process of communication about goals of care and decision making about life-sustaining treatments for hospitalized patients, and to seek opportunities for improvement.

\section{Setting}

Medical wards of three university-affiliated teaching hospitals in Canada.

\section{Method}

At each site, we used drop-in sessions and one-on-one interviews to consult with health care workers on eligible wards to create cross-functional (swim lane) maps of the process of communication about goals of care and decision making about life-sustaining treatments. Healthcare workers 
were also asked about barriers to this process to enable the identification of opportunities for improvement.

\section{Results}

A total of 112 healthcare workers provided input into the creation of process maps across the three sites. Common elements across sites were that: (1) physicians play a central role, (2) the full process for a given patient involves several interactions amongst members of the interprofessional team, and (3) the process is iterative. We also noted between-site variations in the location of $\mathrm{GoC}$ discussions and the extent to which trainees and multi-disciplinary team members were involved. Finally, we identified several key barriers that may serve as targets for future quality improvement efforts: suboptimal location of conversations, insufficient support of physician learners in goals-of-care conversations, and incomplete engagement of the interprofessional team.

\section{Conclusion}

Efforts to improve the quality of goals-of-care discussions and decision making about life-sustaining treatments in the hospital setting need to account for the central role played by physicians in the process but can be enhanced if they can more fully engage the inter-professional health care team.

\section{Resume \\ Contexte}

Une communication de mauvaise qualité sur les objectifs des soins aux patients gravement malades et hospitalisés est associée à une discordance importante entre les ordonnances médicales prescrites pour un traitement de survie et les préférences déclarées des patients. La conception de solutions adaptées à cette discordance nécessite une meilleure compréhension de ce processus de communication.

\section{Objectif}

Acquérir une compréhension détaillée du processus de communication sur les objectifs des soins et la prise de décision sur les traitements de maintien de la vie pour les patients hospitalisés, et rechercher des possibilités d'amélioration.

\section{Paramètres}

Les services médicaux de trois hôpitaux universitaires canadiens affiliés à l'université.

\section{Méthode}

Sur chaque site, nous avons eu recours à des séances d'information et à des entretiens individuels pour consulter les travailleurs de la santé dans les services éligibles afin de créer des cartes interfonctionnelles (couloir de nage) du processus de communication sur les objectifs des soins et la prise de décision sur les traitements de maintien des fonctions vitales. Les travailleurs de la santé ont également été interrogés sur les obstacles à ce processus afin de permettre l'identification des possibilités d'amélioration.

\section{Résultats}

Au total, 112 travailleurs de la santé ont participé à la création de cartes de processus sur les trois sites. Les éléments communs à tous les sites étaient les suivants : (1) les médecins jouent un rôle central, (2) le processus complet pour un patient donné implique plusieurs interactions entre les membres de léquipe interprofessionnelle, et (3) le processus est itératif. Nous avons également 
noté des variations entre les sites en ce qui concerne le lieu des discussions du gouvernement et le degré d'implication des stagiaires et des membres de léquipe pluridisciplinaire. Enfin, nous avons identifié plusieurs obstacles clés qui pourraient servir de cibles aux futurs efforts d'amélioration de la qualité : le lieu sous-optimal des conversations, le soutien insuffisant des apprenants médecins dans les conversations sur les objectifs de soins et l'engagement incomplet de léquipe interprofessionnelle.

\section{Conclusion}

Les efforts visant à améliorer la qualité des discussions sur les objectifs des soins et la prise de décision concernant les traitements vitaux en milieu hospitalier doivent tenir compte du rôle central joué par les médecins dans le processus, mais peuvent être renforcés s'ils peuvent faire participer davantage l'équipe interprofessionnelle de soins de santé.

Keywords: process mapping; hospital medicine, communication; decision making

Hospitalized patients who have serious illnesses, and their family members, have identified communication about goals of care $(\mathrm{GoC})$ and decision making about life-sustaining treatments as important priorities for the improvement of end-of-life care. ${ }^{1}$ In this paper, we define GoC discussions as conversations between clinicians and patients with serious illness, or their substitute decision-makers, about the patient's understanding of illness and prognosis, and the patient's values and priorities related to health care. ${ }^{2}$ These conversations can then inform 'in-the-moment' decisions about treatment, ${ }^{3}$ including decisions to limit the use of certain interventions (e.g., cardiopulmonary resuscitation) should the patient become critically ill. Communicating these decisions includes the documentation of medical orders about the use or non-use of life-sustaining treatments (see Figure 1 for a conceptual framework of end-of-life communication and decision making). ${ }^{4}$ Hospital-based audits of $\mathrm{GoC}$ communication and decision making about life-sustaining treatments have shown that these conversations occur infrequently with patients who have serious illness and that there is substantial discordance between documented medical orders for life-sustaining treatment and patients' stated preferences. ${ }^{5-7}$

Figure 1 depicts refined version of our earlier conceptual framework of end-of-life communication and decision making. ${ }^{4}$ Refinements are based on input from a multi-disciplinary group of 33 individuals from medicine, nursing, social work, clinical ethics, and health policy with expertise in shared decision-making, end-of-life communication and decision making, palliative care, critical care, general internal medicine, and primary care, and 2 family advisors, who attended a research network meeting in September 2015.

Advance care planning (ACP) refers to an upstream communication process-which should occur when patients have decision-making capacity and are relatively well-among patients, family members, future substitute decision-maker(s), and healthcare providers to identify patients' values and preferences about future care.

Goals of care $(\mathrm{GoC})$ discussions become relevant as patients experience serious illness in later life. These are illness-specific, patient-centred conversations framed around illness understanding and prognosis which seek to elicit patients' values, goals, fears, concerns, and acceptable trade-offs that relate to their care.

'In-the-moment decision making' is a shared decisionmaking process, informed by ACP and GoC discussions, to make specific medical decisions about care, including the use or non-use of life-sustaining treatments including cardiopulmonary resuscitation, mechanical ventilation, intensive care unit admission, dialysis, tube feeding, and intravenous hydration.

More and better communication with patients, and among healthcare practitioners, is needed to address this gap in care. ${ }^{8}$ However, communication about $\mathrm{GoC}$ and decision making about life-sustaining treatments are challenging processes to improve because they involve conversations among front line clinicians, patients, and family members in a dynamic clinical environment. To design interventions aimed at improving care in this complex setting, it is necessary to have a detailed understanding of the degree of involvement and interaction among the various members of the health care team in this process and the context in which these processes occur. Indeed, a systematic review found that, compared to usual care, tailored interventions that are based on this kind of understanding are more likely to improve professional practice. ${ }^{9}$

The timing, location, and people involved in conversations about $\mathrm{GoC}$ and decision making about life-sustaining treatments that occur from hospital admission to discharge is a process that can be mapped..$^{10}$ Process maps are visual depictions of steps and connections in a process and can help to clarify roles, identify 


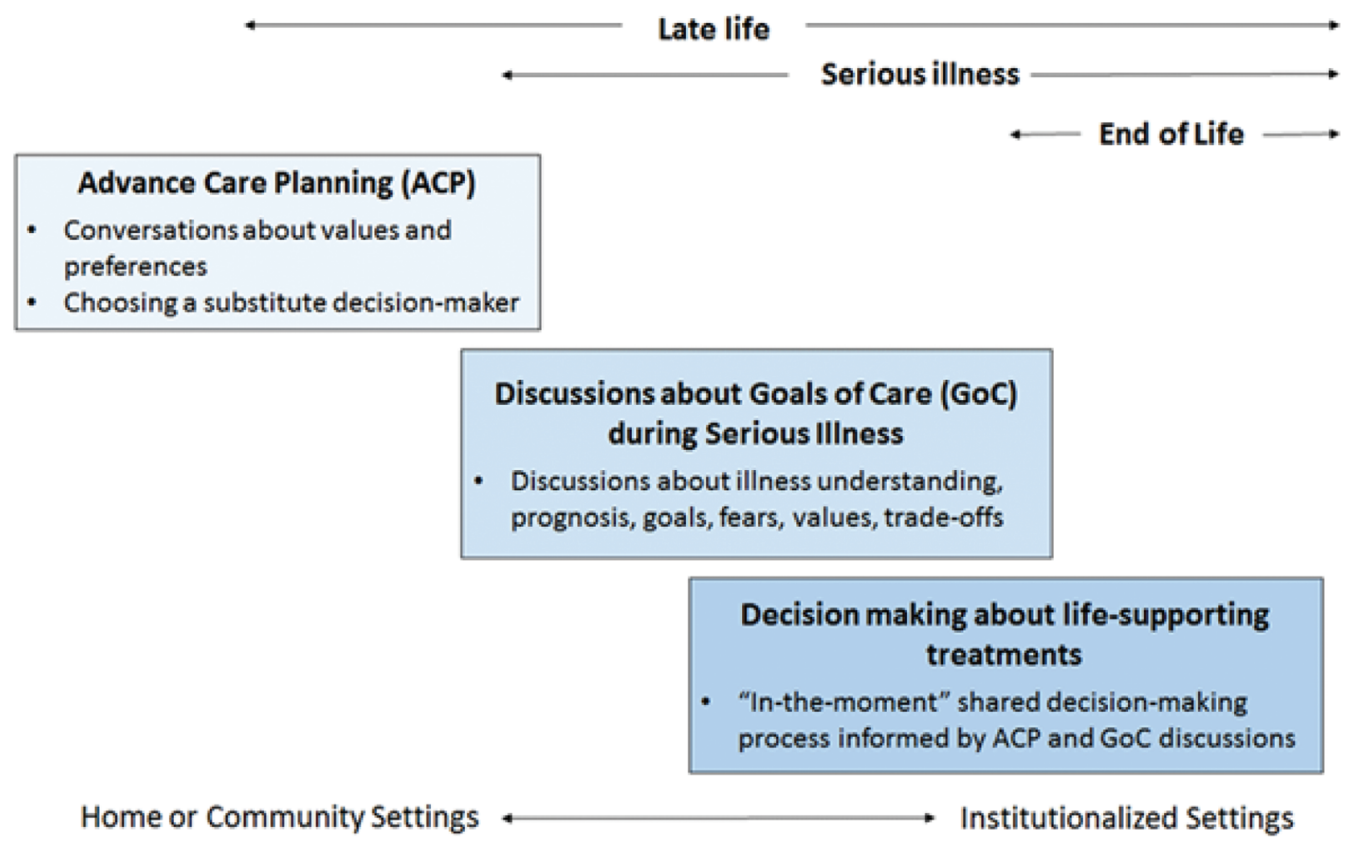

Figure 1. Conceptual framework of end-of-life communication and decision making

redundancies, and highlight areas for improvement. To inform the design of tailored interventions, we developed process maps that describe how GoC discussions occur, how decisions are made about life-sustaining treatments, and how these processes are documented for hospitalized patients. Our primary goal was to describe how these processes occur across the three hospitals. Our secondary objective was to identify barriers to this process to seek opportunities for improvement.

\section{Methods}

\section{Setting}

We conducted this quality improvement study on the Internal Medicine Clinical Teaching Unit (CTU) at each of three Canadian university-affiliated teaching hospitals from three different provinces. All units were staffed with 2 to 3 teaching teams, each consisting of an attending physician who typically changes every 2 to 4 weeks, and 1 to 2 senior residents, 3 to 5 junior residents, and 2 to 4 medical students who typically change every 4 to 6 weeks. In addition to physicians and nurses, the multidisciplinary team at each of the three sites included physiotherapists, occupational therapists, speech-language pathologists, social workers, pharmacists, dieticians, spiritual care workers, and unit clerks. One of the three units also had nurse practitioners, and all units were staffed by nurse managers and nurse educators. The number of beds at each site varied between 36 to 100 and the typical nurse to patient ratio was 1:5. The work conducted in this study was exempt from the research ethics board review because it was deemed a quality improvement activity and did not fall into the category of human subjects research.

\section{Development of Process Maps}

Process mapping is a methodology gaining interest as a tool to inform quality improvement efforts. ${ }^{10}$ For this project, we created cross-functional (also known as swim lane) process maps, to elucidate relationships among various team members and highlight patterns in the workflow. ${ }^{11}$ A patient's entry into the process was defined as the time when a patient was admitted to the medical service in the emergency room or was directly admitted to the medical ward from another institution or ward. The endpoint on the map was defined as the time of discharge from the hospital or the time of transfer to another clinical service.

We developed the process map at each site using an iterative process based on two cycles of consultation with health care workers. Individuals who participated in each cycle of the consultation were a convenience sample of health care workers involved in any aspect of providing or supporting care for patients on the participating medical wards. Consultations consisted of drop-in sessions and one-on-one interviews (sites A and B: drop-in session followed by one-on-one interviews; site C: oneon-one interviews followed by drop-in session). In the drop-in session format, eligible health care workers were invited to a 2 to 3-hour drop-in session during which a large paper copy of a draft process map was posted on the wall. Participants were asked to place "sticky notes" on the draft process map to (1) 
suggest changes to the draft process map that would make it a more accurate representation of the most common or usual processes involved in $\mathrm{GoC}$ communication and decision making about life-sustaining treatments, such that infrequent or rare variations in processes were not mapped, and (2) identify barriers and facilitators to the process of $\mathrm{GoC}$ communication and decision making about life-sustaining treatments. After the drop-in session had ended, a digital photograph of the map was taken to document feedback received from health care workers. In the one-on-one interview format, the project leads presented health care workers with a draft version of the process map and asked them for the same type of feedback as in the drop-in sessions (see above). The project lead at each site kept field notes to document feedback received during each interview. Project leads at each site used data from the field notes or the digital photograph to create an updated draft of the process map and the second round of consultation and revision was undertaken. At each site, the final version of the process map was validated through a member-checking process in which we seek approval for the proposed final version from a subset of health care workers at each site who had participated in earlier stages of the consultation process.

\section{Data Synthesis}

We used a consistent, cross-functional format to depict the final process map from each site (Microsoft Visio, Microsoft Corporation, Redmond, Washington, U.S.). The steering committee, consisting of the project lead from each participating site, reviewed the final maps, field notes, and digital photographs of draft process maps and used a combination of asynchronous e-mail communication and teleconferences to reach consensus on the common elements of GoC communication and decision making about life-sustaining treatments across all 3 sites, and the key barriers and facilitators identified through the process mapping exercise. Since facilitators can be re-framed as barriers and vice versa, these key themes are all presented as barriers for consistency in the Results section below. The steering committee also noted differences observed across sites.

\section{RESULTS}

\section{Study Participants}

The 112 participants in the one-on-one interviews and drop-in sessions conducted at each of the three participating hospital sites to inform the development of the final process maps included nurses, attending staff physicians, specialist physicians from other clinical programs providing consultation services to the attending medical team, residents, medical students, social workers, physiotherapists, unit clerks and other practitioners working on the CTUs (Table 1).
Table 1. Health Care Workers Who Provided Input Into Creation of the Process Maps

\begin{tabular}{|l|c|c|c|c|}
\hline & Site A & Site B & Site C & All sites \\
\hline Nurse & 13 & 7 & 6 & 26 \\
\hline Attending physician & 4 & 4 & 4 & 12 \\
\hline Consultant physician & 0 & 2 & 6 & 8 \\
\hline Resident physician & 11 & 7 & 10 & 28 \\
\hline Medical student & 5 & 3 & 2 & 10 \\
\hline Social worker & 1 & 0 & 1 & 2 \\
\hline $\begin{array}{l}\text { Nurse practitioner or } \\
\text { educator }\end{array}$ & 2 & 2 & 6 & 10 \\
\hline $\begin{array}{l}\text { Other allied health } \\
\text { professionals }\end{array}$ & 2 & 1 & 13 & 16 \\
\hline \begin{tabular}{l} 
Total \\
\hline
\end{tabular} & $\mathbf{3 8}$ & $\mathbf{2 6}$ & $\mathbf{4 8}$ & $\mathbf{1 1 2}$ \\
\hline
\end{tabular}

\section{Current Process of Care At Participating Sites}

The final process maps for the three sites (Figure 2) allowed us to identify three elements that were common to all three sites. First, the treating medical team (attending physicians and residents) on the ward played a central role in $\mathrm{GoC}$ discussions with patients (or their substitute decision-maker[s]) and decision making about lifesustaining treatments. Secondly, the full process involved several interactions among various members of the inter-professional health care team. Finally, the process was iterative in that changes in patients' condition prompted further discussion about $\mathrm{GoC}$ and decisions about life-sustaining treatments.

We also noted variations in the process across sites. First, concerning location, at two sites (A and C), most initial conversations and decisions took place in the emergency department, whereas at the other site (B), most of the conversations and decisions were initiated after the patient had been admitted and physically moved to the CTU from the emergency department. Second, concerning the involvement of other health care workers, at two sites (A and B), nurses were not commonly present during discussions and were not always informed by the medical team about the results of discussions, whereas at site $\mathrm{C}$, nurses were more involved in triggering the medical team to have further $\mathrm{GoC}$ discussions (e.g., when they perceived that current medical orders were not congruent with a patient' sexpressed goals or medical condition) and were more likely to be present during $\mathrm{GoC}$ discussions.

In contrast to Site $\mathrm{C}$, junior residents and medical students were often the primary members of the medical team that had GoC discussions at Sites A and B. The extent of interprofessional involvement also varied, such that at sites A and C, in addition to nurses, several other health professionals, including physiotherapists, occupational therapists, and speech and language pathologists could trigger discussions whereas at Site B they were rarely involved. We also noted that the involvement of 


\section{Jayaraman et al.}

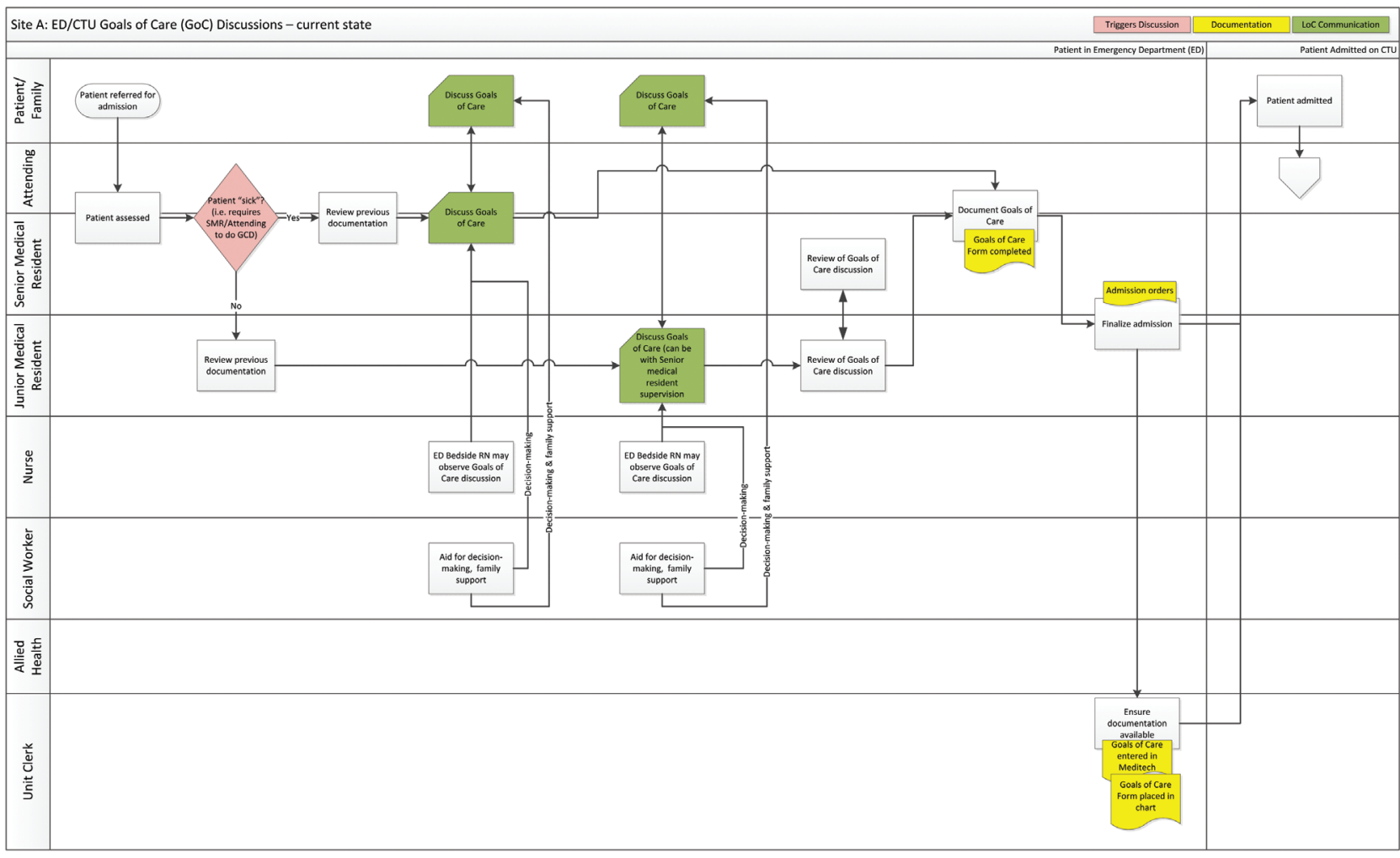

Last Udadat: October 20, 2016

Page 1 of 2

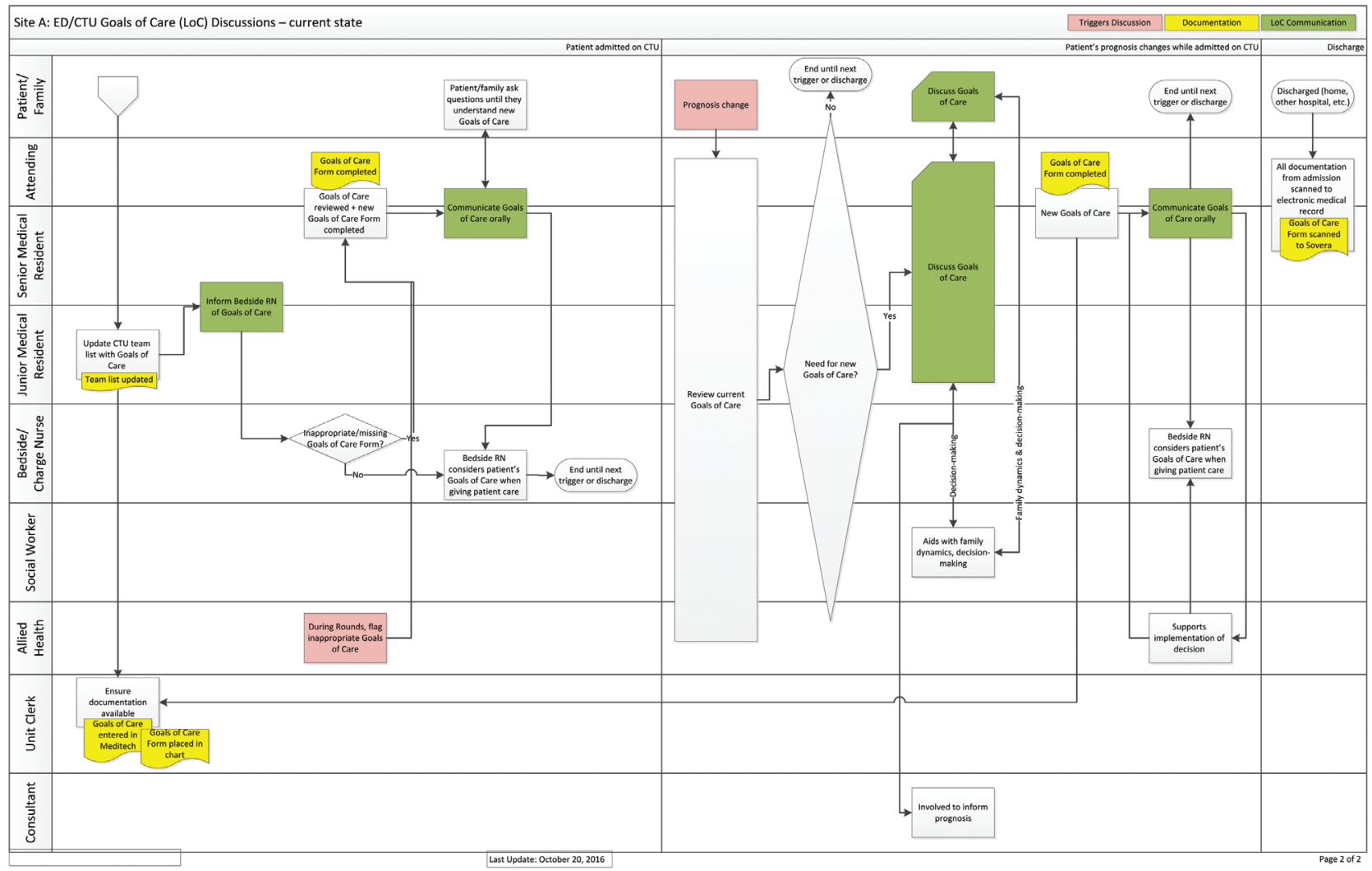




\section{Original Research}
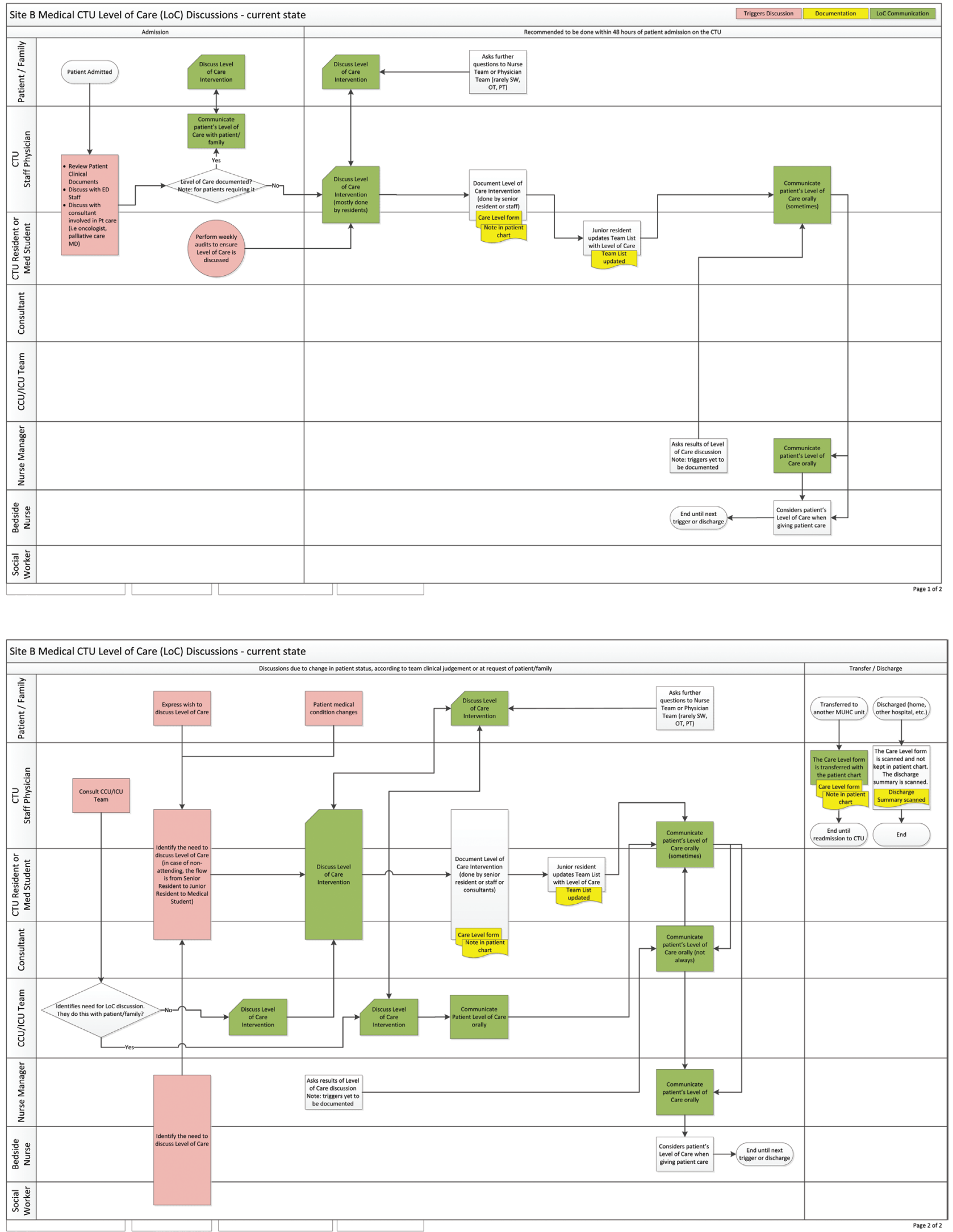


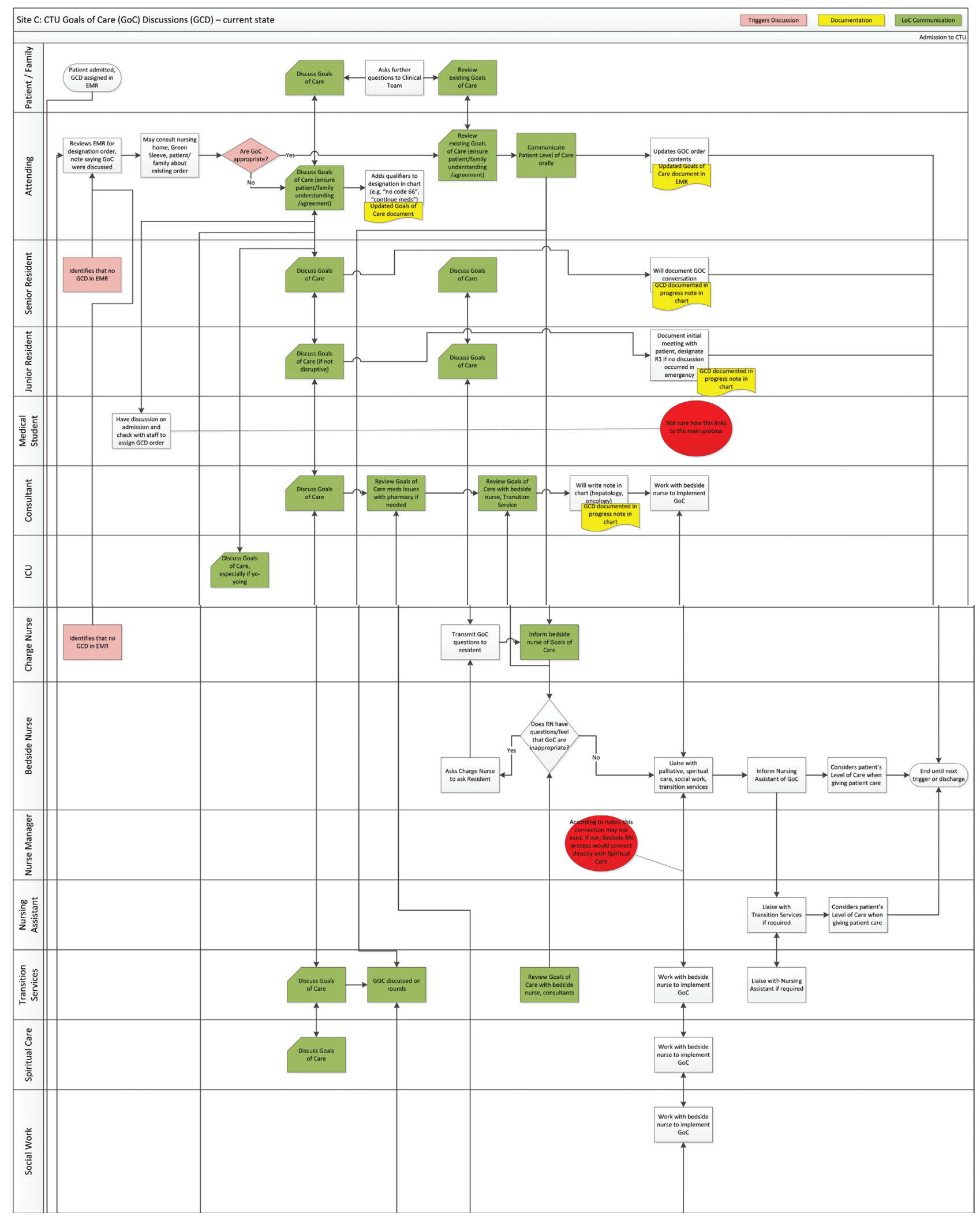




\section{Original Research}

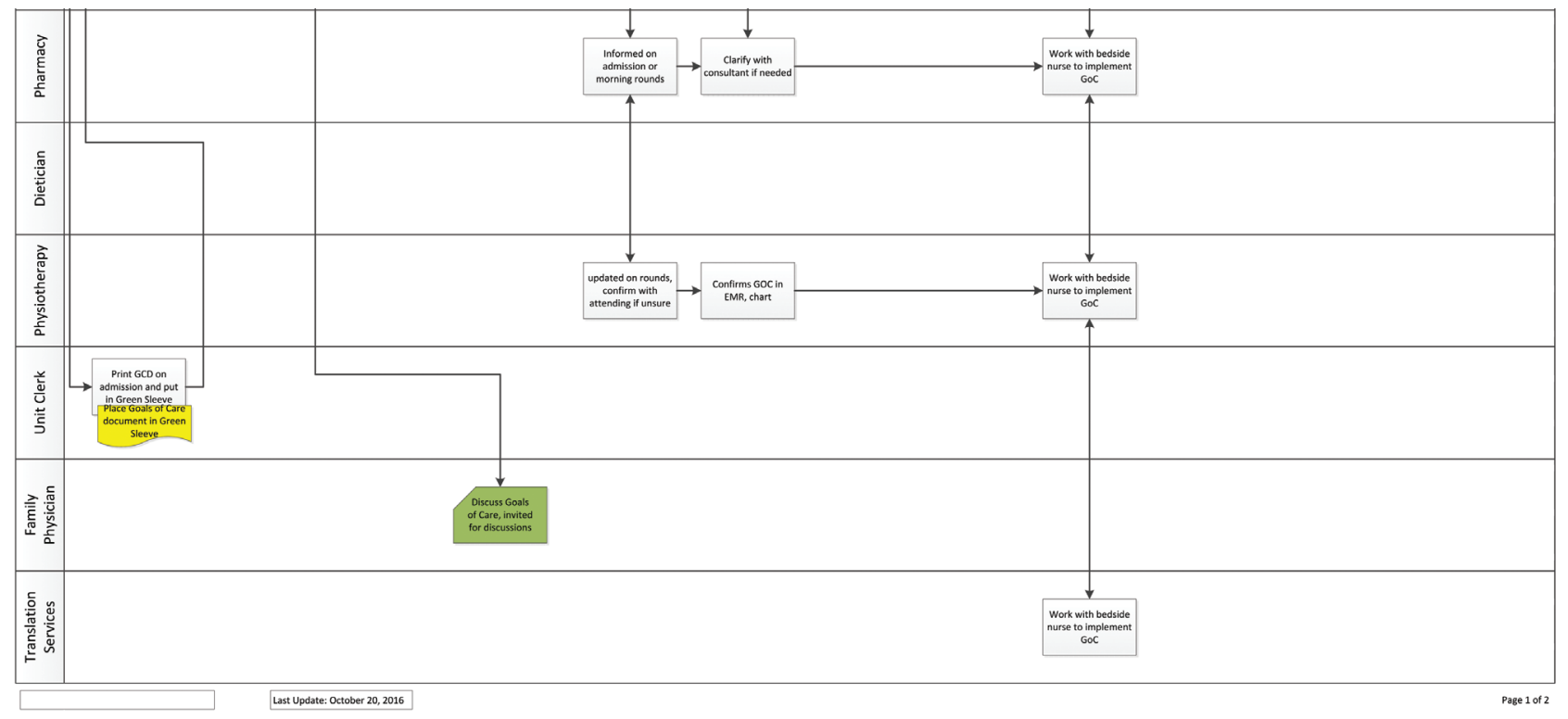

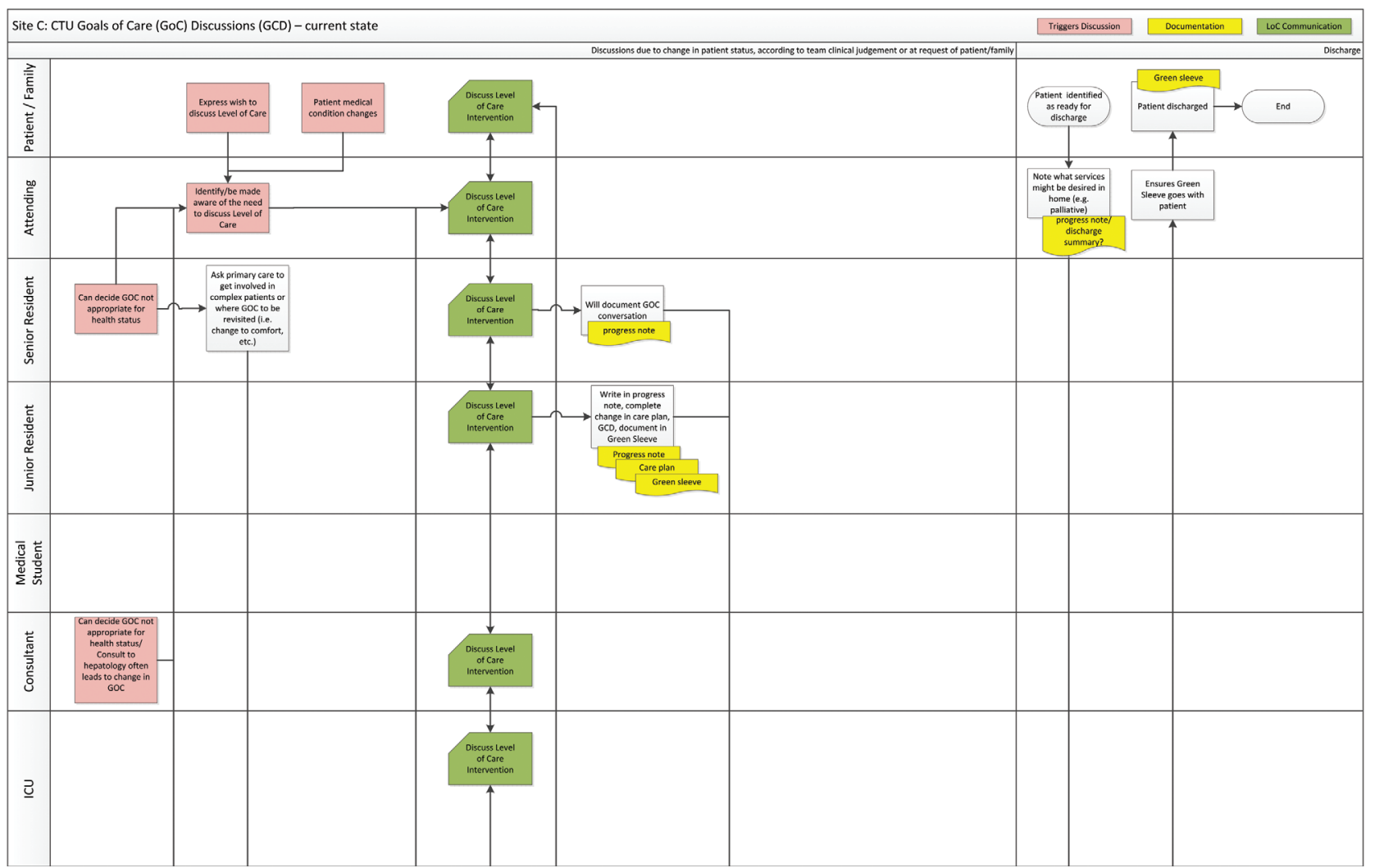




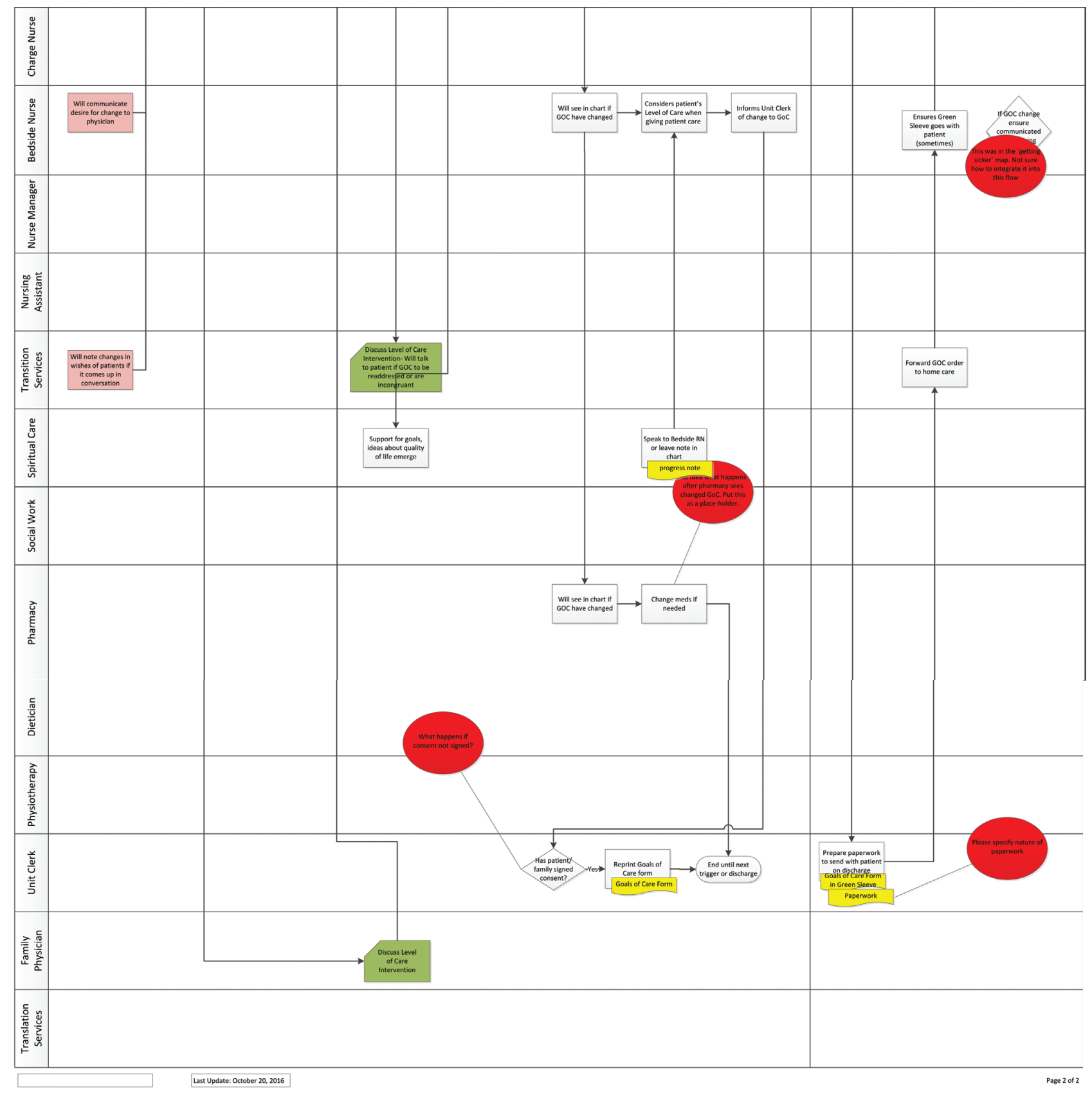

Figure 2. Process maps. Final cross-functional process maps from participating sites (A), (B), and (C). 
consulting physicians was different across sites. There was more involvement during hospital admission of outpatient subspecialists from the patient's circle of care (e.g., oncologists, nephrologists) in $\mathrm{GoC}$ discussions and decision making about life-sustaining treatments at site $\mathrm{B}$, and a more prominent role for palliative care physicians at site $\mathrm{C}$. Finally, concerning documentation of GoC discussions and decisions about life-sustaining treatments, at two sites, unit clerks were responsible for placing physicians' documentation in the medical record about GoC discussions and medical orders for life-sustaining treatments, but at site B, this was the sole responsibility of the medical team. At site C, documentation of $\mathrm{GoC}$ discussions and medical orders for lifesustaining treatments were also systematically communicated to family physicians and accessible in an electronic format in the hospital electronic medical record.

\section{Barriers to GoC Communication and Decision Making about Life-Sustaining Treatments}

Several barriers to GOC communication and decision making about life-sustaining treatments were identified during the process mapping exercise. These included the location of conversations, team interactions, and roles. First, concerning location, a barrier to higher-quality conversations was that discussions were often held in crowded emergency rooms or in multi-bed patient rooms, which do not afford privacy and are prone to distractions.

Second, inadequate support for medical learners was identified as another barrier to effective GoC communication and decision making about life-sustaining treatments. At some of our participating sites, junior residents or medical students were the primary team members having GoC conversations with patients or family members. However, they often undertook these conversations without supervision by more experienced clinicians.

Finally, barriers were identified concerning team interactions and roles. Nurses were often absent from these conversations. This was felt to be due to a lack of time for nurses to join these conversations and physicians initiating these conversations at the physician's convenience. Similarly, other health care workers such as physiotherapists, occupational therapists, speechlanguage therapists, and social workers were variably involved in actual $\mathrm{GoC}$ discussions. Thus, the incomplete engagement of the inter-professional team was identified as a barrier: if members of the inter-professional team are not engaged in the process of GoC communication and decision making about life-sustaining treatments, they are not able to provide optimal support to patients and family members. Insufficient engagement and communication with specialist physicians by CTU teams was identified as another barrier to $\mathrm{GoC}$ communication and decision making about life-sustaining treatments: participants identified that involvement of specialist physicians from the patient's circle of care before admission was inconsistent once the patient was admitted. On the other hand, specialist physicians reported that CTU teams do not always communicate meeting times or results of meetings to them.

\section{Discussion}

Discussing goals of care and decision making about life-sustaining treatments is a complex health care process that, if done well, can improve the quality of care. ${ }^{2,12,13}$ In this quality improvement study, we used process maps to describe how GoC discussions and decision making about life-sustaining treatments take place on the medical wards of three academic hospitals in Canada. Common elements across the 3 sites were that: (1) physicians play a central role in the process, (2) the full process for a given patient involves several interactions among various members of the health care team, and (3) the process is iterative whereby changes in patients' condition prompt further discussions and decisions. Furthermore, we found differences between the 3 sites in the location of GoC discussions (emergency department versus medical ward) and the extent to which trainees and multi-disciplinary team members were involved in $\mathrm{GoC}$ discussions. Although tt was beyond the scope of the study to explore the reasons for the differences between sites, we posit that these practices may have evolved as institutional and provincial cultures over many years.

Our study also identified several barriers to $\mathrm{GoC}$ communication and decision making about life-sustaining treatments in the hospital. In the Box, we summarize these barriers and propose solutions to address each barrier.

Box 1. Barriers and proposed solutions to improve goals-of-care discussions and decision making about life-sustaining treatments for hospitalized patients with serious illness

\section{Barrier}

\section{Proposed Solutions}

Suboptimal location of conversations

Creating and using quiet physical spaces that ensure privacy during conversations

Physician learners leading conversations with inadequate supervision Incomplete involvement and engagement of interprofessional team and consultants
Ensure adequate training, role-modelling, supervision, and coaching

Inter-professional education; use of simulation to strengthen inter-professional communication and collaboration; teamwork training programs

Enact policies or procedures to support the participation of interprofessional team members in conversations including consultants

Enact policies or procedures that empower health care workers to trigger conversations 
One barrier that we identified was the location of GoC conversations in noisy environments that lack privacy such as the emergency department or multi-bed rooms. Although it is not feasible to create new spaces (e.g., private rooms for all admitted patients) in cost and space-constrained hospitals, other processes could be put in place to mitigate this problem. For example, it may be more optimal to wait until a patient is transferred out of the emergency department to a ward setting before engaging in or revisiting in these conversations in more depth Other potential advantages to this approach are that the patient's acute presenting symptoms are likely to have abated and that appropriate family member(s) or substitute decisionmaker(s) can be invited to participate in conversations on the ward. Furthermore, processes could be enacted to mandate that these discussions be held in a private meeting room on the ward whenever possible rather than in a multi-bed patient room. On the other hand, it should be recognized that this may not be possible in all circumstances, for instance, an anticipated rapid deterioration in a patient's condition while in the emergency department. There is a benefit in considering goals of care conversations as an iterative process throughout a hospital admission.

Secondly, we noted that physician learners, including medical students, were leading GoC discussions at some study sites. Although the participation of learners in these critical conversations is an important educational opportunity, the relative inexperience of learners may have an important effect on the quality of these discussions.(14) Indeed, we and others have found that learners often omit important issues when discussing $\mathrm{GoC}$ and engaging in decision making about lifesustaining treatments with patients. ${ }^{15,16}$ Moreover, a recent educational needs assessment for internal medicine residents in the area of palliative and end-of-life care identified GoC discussions as the highest educational priority and highlighted the need for more direct observation of learners with feedback ${ }^{17}$ and programming. ${ }^{18}$ Others have found that internal medicine residents report very infrequent useful feedback from senior residents $(8 \%)$ or attending physicians (7\%) about end-of-life discussions. ${ }^{19}$ Therefore, our findings suggest that more training for learners in the area of GoC discussions is needed and that it will be important to ensure that learners receive sufficient role modelling, direct observation, and feedback from experienced clinicians. The current implementation of competency-based medical education by the Royal College of Physicians and Surgeons of Canada, with appropriate assessment tools, will be an important opportunity to help in this process.

Finally, an important barrier that we identified was the incomplete involvement and engagement of the interprofessional team. These findings may be of interest to others who are seeking to improve the quality of GoC discussions and decision making about life-sustaining treatments in the hospital setting. In a recently published multi-center survey, most hospital-based clinicians, including nurses, rated physicians as the most appropriate persons to have goals of care discussions with patients or family members on medical wards. ${ }^{20}$ This is consistent with our finding that physicians play a central role in GoC discussions at all three sites. Nonetheless, the process maps also showed that multiple disciplines play a part in triggering or supporting the process of discussing $\mathrm{GoC}$, making decisions about life-sustaining treatments, and ensuring documentation in the medical record. Including key inter-professional team members in the process of GoC communication and decision making about life-sustaining treatments can improve team cohesiveness and facilitate the development of a shared mental model. ${ }^{21}$ Greater levels of team member participation can also enhance satisfaction with their role in the team. ${ }^{22}$ Although efforts to involve a greater number of team members in this process runs the risk of creating communication gaps and inefficiencies (if not done well), ${ }^{21}$ it is likely that in a complex health care system, which often involves high-stakes processes and decisions, that greater team involvement, redundancy, and team inter-connectedness is more desirable. Indeed, hospitalbased clinicians have indicated that it would be acceptable to them for a wide range of healthcare professionals, including nurses and social workers, to be involved in different aspects of discussing $\mathrm{GoC}$ with patients and families. ${ }^{20}$ As such, our findings suggest that GoC communication and decision making about life-sustaining treatments in a hospital setting may be better conceived as a team process than as the function of physicians alone. Therefore, interprofessional education, the use of simulation to strengthen interprofessional communication and collaboration, and teamwork training programs such as TeamSTEPPS may have a role in improving $\mathrm{GoC}$ communication and decision making about life-sustaining treatments in hospital. ${ }^{23-25}$ To legitimize the implementation of these or other initiatives to enhance interprofessional collaboration, hospitals could enact policies or procedures that either support attendance and participation of interprofessional team members in $\mathrm{GoC}$ discussions or that allow them to be updated on the content of GoC discussions after they have occurred.

Our study has several strengths including the use of an explicit template for process mapping, the conduct of the study at multiple centres, and broad consultation with a diverse sample of health care workers to obtain feedback on the accuracy of the maps. However, our study also has some limitations. The main limitation is that we only carried out our process mapping activity at three Canadian teaching hospitals and so our findings are unlikely to be transferable to non-academic hospitals where 
learners are absent or minimally present, or to hospitals in other countries. Also, we did not solicit input from patients or families in the development of the process maps.

From this quality improvement study on the medical wards of three Canadian teaching hospitals, we conclude that efforts to improve the quality of GoC discussions and decision making about life-sustaining treatments in the hospital setting need to account for the central role played by physicians in the process and can be enhanced if they can more fully engage the interprofessional health care team. Also, the location of conversations and better learning opportunities for physician learners are important factors in improving the quality of these discussions. The site-specific and general themes that emerged from this study have already informed the design of an ongoing, multi-site implementation study focused on improving $\mathrm{GoC}$ conversations on the same medical wards that participated in this study. For instance, formalized planning for $\mathrm{GoC}$ discussions will encompass the inclusion of appropriate interprofessional health care team members and the choice of a suitable location for the conversation. Similarly, our findings can inform future efforts at other institutions to improve the quality of communication and decision making with hospitalized patients who have a serious illness so that they can ultimately receive care that is more consistent with their goals.

\section{Acknowledgements}

The authors are indebted to and would like to thank the health care workers from participating in clinical teaching units who provided their input into the creation of the process maps. The authors would also like to thank Brian Bradley for assisting with graphical formatting and layout of the process maps.

\section{Contributorship Statement}

Dev Jayaraman conceived of and designed the study, contributed to data acquisition, analysis, and interpretation, drafted the manuscript, gives final approval of the version to be published, and takes responsibility as the guarantor for the overall content of the work.

Nishan Sharma contributed to data acquisition, analysis and interpretation, revised the manuscript critically for important intellectual content and gives final approval of the version to be published.

Alannah Smrke contributed to data acquisition, analysis and interpretation, revised the manuscript critically for important intellectual content and gives final approval of the version to be published.

Jessica Simon contributed to data acquisition, analysis and interpretation, revised the manuscript critically for important intellectual content and gives final approval of the version to be published.

Peter Dodek contributed to data analysis and interpretation, revised the manuscript critically for important intellectual content, and gives final approval of the version to be published.

Daren Heyland contributed to data analysis and interpretation, revised the manuscript critically for important intellectual content, and gives final approval of the version to be published.

John You conceived of and designed the study, contributed to data acquisition, analysis, and interpretation, drafted the manuscript, gives final approval of the version to be published, and takes responsibility as the guarantor for the overall content of the work.

\section{Conflicts of Interest}

Dr. Jessica Simon is Physician Consultant to Advance Care Planning and Goals of Care, Alberta Health Services, Calgary Zone. The remaining authors have no conflicts of interest to disclose.

\section{Funding}

This work was funded by a research grant (CORE2013-30) from the Canadian Frailty Network (www.cfn-nce.ca) in partnership with Montreal General Hospital, Montreal, Hamilton Health Sciences, Hamilton, and W21C and Foothills Medical Centre, Calgary, all in Canada.

\section{References}

1. Heyland DK, Cook DJ, Rocker GM, Dodek PM, Kutsogiannis DJ, Skrobik $\mathrm{Y}$, et al. Defining priorities for improving end-of-life care in Canada. CMAJ 2010;182(16):E747-E52.

2. Bernacki RE, Block SD. Communication About Serious Illness Care Goals: A Review and Synthesis of Best Practices. JAMA Intern Med. 2014;174(12):1994-2003.

3. Sudore RL, Fried TR. Redefining the "planning" in advance care planning: preparing for end-of-life decision making. Ann Intern Med 2010;153(4):256-61.

4. Sinuff T, Dodek P, You JJ, Barwich D, Tayler C, Downar J, et al. Improving End-of-Life Communication and Decision Making: The Development of a Conceptual Framework and Quality Indicators. J Pain Symptom Manage 2015;49(6):1070-80.

5. Heyland DK, Barwich D, Pichora D, Dodek P, Lamontagne F, You JJ, et al. Failure to engage seriously ill hospitalized patients and their families in advance care planning: results of a multicenter prospective study. JAMA Intern Med 2013;173(9):778-87.

6. You JJ, Dodek P, Lamontagne F, Downar J, Sinuff T, Jiang X, et al. What really matters in end-of-life discussions? Perspectives of patients in hospital with serious illness and their families. CMAJ 2014;186(18):E679-87.

7. Heyland DK, Ilan R, Jiang X, You JJ, Dodek P. The prevalence of medical error related to end-of-life communication in Canadian hospitals: results of a multicentre observational study. BMJ Qual Saf 2016;25(9):671-9.

8. Roze des Ordons AL, Sharma N, Heyland DK, You JJ. Strategies for effective goals of care discussions and decision-making: perspectives from a multicentre survey of Canadian hospital-based healthcare providers. BMC Palliat Care 2015;14:38. 
9. Baker R, Camosso-Stefinovic J, Gillies C, Shaw EJ, Cheater F, Flottorp S, et al. Tailored interventions to overcome identified barriers to change: effects on professional practice and health care outcomes. Cochrane Database Syst Rev 2010(3):CD005470.

10. Trebble TM, Hansi N, Hydes T, Smith MA, Baker M. Process mapping the patient journey: an introduction. BMJ. 2010;341:c4078.

11. Damelio R. The Basics of Process Mapping. 2nd ed. Boca Raton, FL: CRC Press; 2011.

12. Quill TE. Perspectives on care at the close of life. Initiating end-of-life discussions with seriously ill patients: addressing the "elephant in the room". JAMA 2000;284(19):2502-7.

13. Leung JM, Udris EM, Uman J, Au DH. The effect of end-of-life discussions on perceived quality of care and health status among patients with COPD. Chest 2012;142(1):128-33.

14. Loertscher LL, Beckman TJ, Cha SS, Reed DA. Code status discussions: agreement between internal medicine residents and hospitalized patients. Teach Learn Med 2010;22(4):251-6.

15. Shah K, Swinton M, You JJ. Barriers and facilitators for goals of care discussions between residents and hospitalised patients. Postgrad Med J 2017;93(1097):127-32.

16. Tulsky JA, Chesney MA, Lo B. How do medical residents discuss resuscitation with patients? J Gen Intern Med 1995;10(8):436-42.

17. Roze des Ordons A, Ajjawi R, Macdonald J, Sarti A, Lockyer J, Hartwick M. Palliative and end of life care communication as emerging priorities in postgraduate medical education. Can Med Educ J 2016;7(1):e4-e21.
18. Roze des Ordons A, Kassam A, Simon J. Goals of care conversation teaching in residency - a cross-sectional survey of postgraduate program directors. BMC Med Educ 2017 Jan 6;17(1):6

19. Buss MK, Alexander GC, Switzer GE, Arnold RM. Assessing competence of residents to discuss end-of-life issues. J Palliat Med 2005;8(2):363-71.

20. You JJ, Downar J, Fowler RA, Lamontagne F, Ma IW, Jayaraman D, et al. Barriers to goals of care discussions with seriously ill hospitalized patients and their families: a multicenter survey of clinicians. JAMA Intern Med 2015;175(4):549-56.

21. D’Ambruoso SF, Coscarelli A, Hurvitz S, Wenger N, Coniglio D, Donaldson D, et al. Use of a shared mental model by a team composed of oncology, palliative care, and supportive care clinicians to facilitate shared decision making in a patient with advanced cancer. J Oncol Pract 2016;12(11):1039-45.

22. Phillips JM. The role of decision influence and team performance in member self-efficacy, withdrawal, satisfaction with the leader and willingness to return. Org Behav Human Dec Processes. 2001;84(1):122-47.

23. Murdoch NL, Bottorff JL, McCullough D. Simulation education approaches to enhance collaborative healthcare: a best practices review. Int J Nurs Educ Scholarsh 2014;10.

24. Quality AfHRa. TeamSTEPPS: Strategies and Tools to Enhance Performance and Patient Safety. Washington, D.C.; 20062006.

25. Ferguson SL. TeamSTEPPS: integrating teamwork principles into adult health/medical-surgical practice. Medsurg Nurs 2008;17(2):122-5. 